\title{
Una mirada en torno al libro Apuntes para un Náufrago (Letra Maya, Editorial, 2017), de Paul Benavides Vílchez
}

\author{
A look into Apuntes para un Náufrago [Notes for a \\ Shipwrecked Sailor] (Letra Maya, Eds., 2017), by Paul \\ Benavides Vílchez
}

\section{Um olhar ao redor do livro Apuntes para un náufrago \\ [Anotações para um náufrago] (Letra Maya, Eds. 2017) do autor Paul Benavides Vílchez}

Por Mía Gallegos

Paul Benavides Vílchez escri-

be este libro en prosa, y en él parece rememorar la incertidumbre que vivimos desde la década del ochenta. Podría decirse que se trata de un mismo periodo históri$\mathrm{co}$, una época con sus heridas y sus fisuras. A través de estas fisuras se cuelan las palabras de Paul, son las memorias de un náufrago, que bien puede ser él mismo o todos nosotros, quienes lo leemos en este preciso momento.

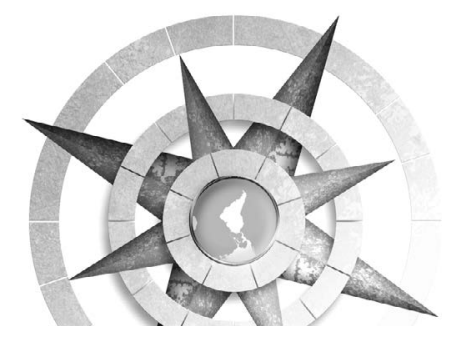

El libro es un largo poema en prosa poética, cuya atmósfera existencialista es lo más sobresaliente. Se trata de la creación de sensaciones donde se mezclan la nostalgia y la incertidumbre. Con la ayuda y con los temas que en ocasiones plantea Octavio Paz en sus ensayos, como por ejemplo en El arco y la lira, pretendo adentrarme en este tomo.

En primer término, quiero detenerme en una definición que $\mathrm{Paz}$ ofrece en el libro ya citado: "La poesía es conocimiento, salvación, poder, abandono. Operación capaz de cambiar al mundo, la actividad poética es revolucionaria por naturaleza; ejercicio espiritual, es un método de liberación interior." 
En efecto, encuentro en esta definición una pista para adentrarme y para deleitarme también en este largo poema, poema de oscuridades, de poemas nocturnales, de poemas donde también hay fogonazos de luz. Hay un conocimiento en estas prosas, hay un "algo" que se nos devela, es un mundo visto desde las entrañas; pero también es un mundo visto a partir de una realidad que se observa con toda la incertidumbre. Se trata del destino del náufrago, del encallamiento, si cabe, en una realidad que lastima, agrede y que hace que lo vivido se transmute.

Todo parece indicar un periplo, o más bien dos periplos: uno hacia destinos geográficos reconocibles, como Cuba, por ejemplo; otro el de lo que se percibe en ocasiones en forma amenazante. La salvación es de otra naturaleza, se salva lo que ha estado oculto y se transforma en la palabra, en estas prosas. La escritura es, sin duda, un ejercicio espiritual, un método de liberación interior, tal y como lo apunta Paz. Mas en este libro, tal y como el autor lo señala en una de sus prosas, es un viaje de iniciación.

Pero me he quedado tan solo en las palabras de $\mathrm{Paz}$, sin adentrarme propiamente en las prosas de Paul. El libro está dividido en tres secciones, a saber, una botella lanzada al mar; el viaje del náufrago y, en tercer lugar, después del naufragio. Se trata de tres momentos que están entrelazados, en parte por la negregura de la noche, la oscuridad de un tiempo incierto y por una noción de amor que no logra cuajar. Es como si todo lo que prosa quedara inconcluso, dicho así de sopetón como para no olvidarlo, son apuntes que no parecen haber sido escritos a la ligera sino suavemente, muy reflexionados.

Empieza hablando del humo en la primera prosa, ahí donde todo se disuelve, donde nos permite observar una realidad en claroscuro, se trata de un orbe sumergido, que al contacto con la palabra emerge.

En la segunda prosa, Paul rememora su infancia y establece comparaciones muy inusitadas como las que cito a continuación: "Ahí está la patria de la infancia entre juguetes de plomo y loros de lengua absuelta. Es una selva cósmica de orugas de luna verde, monos crepusculares y gatos pardos en la punta del aire."

Mas también hace alusión al tema que inicia este segmento cuando habla de una botella lanzada al mar: "Es una ventana abierta para fugarse cuando el miedo arrecia y el padre tensa el lienzo para pintar un

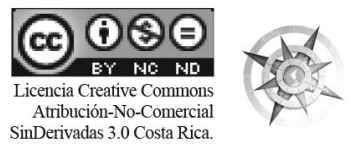


hombre y una botella triangular con glaciares fogatas de eucalipto."

Un hombre que lanza una botella al mar, ¿qué busca? ¿Qué intenta? ¿Acaso la salvación? ¿Es que acaso en este mundo podemos salvarnos así, de manera individual, atados como estamos unos a otros?

En la prosa número tres nos habla de su abuela, establece vínculos de amor, pero en la prosa que sigue, en la número cuatro nos presenta un contexto histórico y pone una fecha de manera precisa y dice así: "Una bandera negra y roja ondea lenta contra el cielo azul de diciembre de 1977. Una mujer colecta fondos para derrocar al tirano que estaba a un poco más de 400 kilómetros al norte."

Es la época de la guerra centroamericana, época cruenta, luego de la cual muchos conflictos aún no han sido resueltos y en muchos casos, más bien han empeorado, en especial si se trata el tema de la pobreza y las desigualdades.

Leo ahora la prosa número ocho, en la que Paul hace una evocación a la noche. Este texto y en realidad el libro en su totalidad, tienen la magia de la poesía maldita baudeleriana. De esta prosa señalo algunos fragmentos.
Dice el poeta: "La muerte levanta el velo de la noche, busca entre los sobrevivientes a pintores, panaderos, diletantes de brocha gorda, arrasa a tías adictas a la locura y a las taras en hospitales y sanatorios. La muerte, siempre la muerte en las instancias hediondas del sueño, en la presunción de la propia muerte a manos de un zarpazo inexplicable."

Aquí el autor nos muestra a los seres indefensos y sin nombre, a los excluidos de todas las sociedades y que deambulan por las urbes. Nombra a los artesanos, a los locos, a esas tías adictas y nos habla propiamente de la muerte.

Sí; el tema de la muerte está presente, es el principal, más lo cierto es que la incertidumbre recorre cada una de las páginas. La incertidumbre y el azar, porque ¿no es cierto que lanzar una botella al mar es de por sí un acto azaroso?

Sin embargo, esta prosa número ocho alude también a la madre. En realidad, se trata de una invocación muy fuerte porque quien escribe es un doliente. Es un texto que habla del dolor, del desprendimiento, del vínculo más hondo que existe. Es preciso detenerse a leer un trozo de ese poema: 
La muerte, la muerte, la muerte, la muerte de la madre en vida, desde antes de la vida, legó esa herencia que se lleva sin saberlo, ese fantasma inclemente y ubicuo que aparece en las instancias rotas del día y de la noche. Ángel del miedo que nace en las horas en que un cuerpo parece colmar de humedad los rincones inexplicables del desamparo y una mano desata todo lo que se parece al amor y a la ternura.

Aquí me detengo, este texto es mi propia historia, si bien escrita por otro, es mi propio testimonio y me hermana con el autor. Muerte, amor, ternura y todo se disuelve y retorna a lo increado.

En la prosa número diez, este náufrago sorprende. Ojalá sea yo quien encontró esta carta en la botella que se lanzó al mar. El texto tiene música, posee ritmo y vale la pena detenerse a leerlo:

Me afirmo en la vocación de marino $o$ de nube. Fundo un paraíso entre los zarpazos de lo estatuido y las proclamas absurdas del éxito. Quemo las palabras que plantaron desde antes de la muerte en el plexo y en mi frente. Retiro cada letra, cada sello de fuego y pongo en su lugar el desafuero del amor y del cuerpo. Veo la propia vida como un río que arrasa aquella fe endurecida por siglos de estupidez, que no podía nombrar el mar sin vaciarlo de memoria y sal.
Es importante observar el vínculo que traza el poeta entre el marino y la nube porque hay en esta asociación de palabras un sentimiento de levedad. Mientras que el marino es un ser humano, la nube simplemente boga por los cielos. Pero al utilizar la conjunción o, los asemeja y son de igual condición. Y, por otra parte, el último renglón donde expresa que no podría nombrar el mar sin vaciarlo de memoria y de sal, me remite a mí al intento de vaciar su propio inconsciente. En verdad lo hace en este acto de escritura.

Ahora quiero detenerme en la segunda parte del libro que lleva el título del viaje del náufrago. Ciertamente el yo poético realiza un periplo, un viaje de iniciación, pero también se detiene en el mundo de los bares y en el de la burocracia ministerial. En toda esta segunda parte del poemario se siente una atmósfera existencialista que me hizo evocar tanto a Albert Camus como a Jean Paul Sartre, dos autores, que al parecer es preciso que retornen a este mundo globalizado carente muchas veces de ideales más nobles y de pensamiento más crítico.

La atmósfera existencialista, de la vida del submundo está aquí. Este náufrago en tierra no tiene a donde asirse, de manera que la única

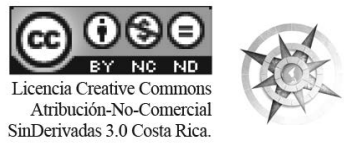


opción ética es escribir y describir lo que se vive. Para ello vale la pena detenerse en lo que dice: "Resistió el ácido de la soledad, sus cabos sueltos, los vicios agudos del silencio, la palabra frívola que declinaba hacia su extinción. Prescindió de un cuerpo amable para no hollar la arena de la playa juntos y no morir al unísono. Fue un lince para escapar por algún paraje inédito del ser ¿Quién era entonces?" ¿No es cierto que interrogarse y bucear en las profundidades es propio de los existencialistas? Desde esa óptica escribe Paul Benavides Vílchez.

Y este transitar del poeta o del náufrago o del simple caminante que atraviesa las urbes, lo hace por medio de la lectura y de la nostalgia y así exclama: "Allí la cerveza sabía dulce y la nostalgia era el rincón de los parias. Izaba la bandera frente los últimos acontecimientos satelitales y la diáspora de polvo de un muro que se caía a miles de kilómetros de distancia. Iba a la caverna donde encallaban siempre los que se resistían a cambiar, los rebeldes a dejar de ver el cielo a través de los ojos de un niño." Aquí el autor detalla el naufragio, la pérdida, la incertidumbre y la mirada inocente.

Mas la mirada inocente no siempre está presente. Una realidad donde se mezclan la guerra, la paz y los efluvios etílicos también aflora. Aquí el poeta actúa más bien como un cronista de su tiempo y dice: "Frecuenté los lugares improvisados donde la pasión tutelar izó la bandera del desencanto. Celebré con vasos cargados de vino o ron nicaragüense el fuego de la vida. Abracé la puesta en marcha de alguna idea entre fumarolas de tabaco rancio y una mujer sifilítica. La paz, la guerra, un nuevo Vietnam, la muerte, Centro América iqué mierda!"

La segunda parte del libro culmina con la prosa número cuarenta y ocho y tal parece que aquí el poeta nos remite al aprendizaje que le deparan las mujeres con sus artes amatorias. Este texto, que abunda en verbos es de una gran vitalidad y movimiento, tal como si en música que cerrara con un estruendoso sonido de percusión. Alude a las mujeres y a la primavera, como esperanza, como un camino que se abre luego de naufragar.

En la tercera parte del poemario, que lleva el título de después del naufragio, Benavides se enfrenta a la caída del mundo bipolar, al fin de la guerra fría y dice así: "Me aparté de los fuegos fatuos de la militancia para entender la seductora verdad de la carne. ¿Cómo ordenar a los hombres por números, gradaciones, lealtades, dogmas?"

¿Será cierto que se derrumbaron las ideologías? ¿No será que más bien hay 
que volver a pensar? Y por los vientos que corren por este mundo, Camus y Sartre tienen mucho que explicarnos. Al menos para quien escribe estos pensadores no han perdido vigencia en lo más mínimo. El tomo Moral y Política de Albert Camus debería ser un libro de cabecera.

Si se da un quebranto en la sociedad, si no hay ya un asidero, si se abandona la noción de la utopía, entonces me pregunto: ¿cuál es el camino? En parte el examen permanente de la realidad; pero muy especialmente permitirse vivir la temporada en el infierno baudeleriana para aprender de ella y salir como se sale de un remolino.

Esta crónica poética pinta la realidad del desamparo, se recurre a la metáfora del naufragio para hablarnos de la náusea que nos sacude. Mas Paul toma partido por la cordura aun cuando esta duela y dice así: "Heme aquí, entonces, limpio, sobrio, quieto, muerto, en el interminable desconsuelo de la cordura, entre alcoholes huidos sin probar, sin el olor cálido del sexo en la punta del aliento."
La poética de Paul no es la de la ensoñación que con tanto acierto habló Gastón Bachelard. Es la poética de un mundo que se derrumba y que entra en una larguísima transición. El poeta no lo sabe y tan solo lo intuye, por lo tanto, transcribo su decir:

"Nadie intuye el sonido de la catástrofe a escasos metros del sueño. Era imposible prever las hordas invisibles de la historia derribando murallas, tiempos, dogmas, tribus partidos, bandos, núcleos y comités. Cómo prever el silencio que se impondría en las mesas de bares y los lugares propios para el amor y el deseo. El silencio impuesto en las bocas y las palabras arrasaría las colmenas donde las abejas tramaban su revuelta de miel y primavera."

Aquí concluyo mi lectura. Un lector más profundo y autorizado hallará nuevos senderos. Cierto que el mundo que nos dibuja es de soledad, desamparo, incertidumbre y desprendimiento. Es una temporada en el infierno. Mas es un mundo visto desde la lucidez. Me parece que ese es el camino a seguir. 